\title{
Effects of metal ions on the activity and stability of peroxidase in Tartary buckwheat shoots
}

\author{
Daisuke Mikami ${ }^{1}$, Hideyuki Kurihara ${ }^{1}$, Koretaro Takahashi $^{1}$, Tatsuro Suzuki ${ }^{2}$, \\ Toshikazu Morishita ${ }^{3}$ \\ ${ }^{1}$ Faculty of Fisheries Sciences, Hokkaido University, Hakodate, Japan \\ ${ }^{2}$ National Agriculture and Food Research Organization, Hokkaido Agricultural Research Center, Sapporo, Japan; \\ Corresponding Author: tsuzu@affrc.go.jp \\ ${ }^{3}$ National Agriculture and Food Research Organization, Hokkaido Agricultural Research Center, Memuro Upland Farming Research \\ Station, Memuro, Japan
}

Received 1 May 2013; revised 17 June 2013; accepted 2 July 2013

Copyright (C) 2013 Daisuke Mikami et al. This is an open access article distributed under the Creative Commons Attribution License, which permits unrestricted use, distribution, and reproduction in any medium, provided the original work is properly cited.

\begin{abstract}
This is the first report to purify and characterize POX in shoots of buckwheat species. POX was partially purified from Tartary buckwheat shoots by 48.0 fold with a final yield of $9.07 \%$. During ion-exchange and gel filtration chromatography, only one peak corresponding to POX activity was found. The molecular weight of POX was determined to be $37.5 \mathrm{kDa}$ using gel filtration chromatography. The optimal pH of POX activity was 5.5 (guaiacol, quercetin) and 5.0 (ABTS). The $K_{m}$ of POX activity was $22.3 \mathrm{mM}$ (guaiacol), $6.3 \mathrm{mM}$ (ABTS) and $0.92 \mathrm{mM}$ (quercetin). In contrast, the $K_{m}$ for quercetin in the presence of $\mathrm{Fe}^{3+}$ ions was two orders of magnitude less $(0.018 \mathrm{mM})$ than that in its absence. The stability of POX activity was increased in the presence of trivalent metal ions, even after $186 \mathrm{~h}$ in solution. POX activity was retained by $83.6 \%$ and $56.1 \%$ in the presence of $1 \mathrm{mM} \mathrm{Fe}^{3+}$ and $\mathrm{Al}^{3+}$ ions, respectively, whereas it was completely inactivated in their absence. To the best of our knowledge, this is the first study to detail the activation and stabilization of POX activity in relation to trivalent metal ions.
\end{abstract}

Keywords: Tartary Buckwheat; Characterization; Peroxidase; Metal Ion; Quercetin; $K_{m}$

\section{INTRODUCTION}

Buckwheat is a rich source of functional polyphenols such as rutin and quercetin [1-4]. Tartary buckwheat leaves contain rutin and anthocyanins in high concentrations (rutin: ca $100 \mathrm{mg} / \mathrm{g} \mathrm{DW}$, anthocyanin: ca $0.8 \mathrm{mg} / \mathrm{g}$
DW) $[5,6]$. For plants, the physiological roles of polyphenols are reported to provide UV-B protection and have antimicrobial properties [7]. Although some physiological roles of polyphenols, including UV screening, anti-desiccation and anti-cold stresses [5], related to stress resistance have been studied in buckwheat, the roles of polyphenols still remain unclear.

On the other hand, plants have polyphenol-oxidizing enzymes such as peroxidase, which is related to lignification [8] and resistance against infection by pathogens. Tartary buckwheat (Fagopyrum tataricum) shoots contain a substantial amount of peroxidase (POX) activity, the characteristics and physiological roles of which have not been studied. Peroxidases are classified by various categories on the basis of substrate specificity and comparison of amino acid sequences. For example, ascorbate peroxidase (APX, EC 1.11.1.11) and plant peroxidase (POX, EC 1.11.1.7) are heme-containing proteins and glutathione peroxidase (GPX, EC 1.11.1.9) is a protein that forms oxidized glutathione, which is related to antioxidants and detoxification. POXs are considered to have different properties in different tissues [8]. Therefore, characterization of POX is important in order to understand the physiological roles of polyphenols in buckwheat leaves.

POX has been partially purified and characterized in both common ( $F$. esculentum) and Tartary buckwheat seeds $[9,10]$. These reports revealed that POX consists of at least two isozymes and has a lower $K_{m}$ for phenolic substrates such as quercetin and guaiacol than other substrates. However, to the best of our knowledge, the purification and characterization of POX in buckwheat shoots has not yet been reported in buckwheat species. Some papers have described POX as being activated by $\mathrm{Ca}^{2+}, \mathrm{Fe}^{3+}$ or $\mathrm{Al}^{3+}$ ions $[21,22]$. Some kinds of POX pro- 
tein have been reported to contain metal ions, but $\mathrm{Ca}^{2+}$ sometimes inhibited POX activities [23]. These reports revealed the importance concerning the effects of metal ions on POX activity in studying the physiological roles of POX. Therefore, we investigated the effects of metal ions on purified POX activities as well.

\section{MATERIALS AND METHODS}

\subsection{Plant Material}

Tartary buckwheat (F. tataricum var. Hokkai T10) was grown in the experimental field at the National Agricultural Research Center for the Hokkaido Region in Memuro, Hokkaido, Japan. On June $7^{\text {th }}, 2012$, shoots grown to 5 days after germination were collected and stored at $-80^{\circ} \mathrm{C}$ until they were used.

\subsection{Extraction and Purification of $P O X$}

Buckwheat shoots (20 g fresh weight) were homogenized with $200 \mathrm{ml}$ of extraction buffer containing $50 \mathrm{mM}$ acetate-LiOH buffer (pH 5.5) and $0.3 \%$ TritonX-100 (v/v) for $30 \mathrm{~min}$ according to the method in previous report [11]. A crude enzyme solution was obtained by centrifugation and then precipitated with $0 \%-80 \%$ saturation of solid $\left(\mathrm{NH}_{4}\right)_{2} \mathrm{SO}_{4}$. The precipitate was dissolved in buffer A, which contained $50 \mathrm{mM}$ acetate- $\mathrm{LiOH}$ buffer ( $\mathrm{pH}$ 5.5), and dialyzed. The dialyzed enzyme solution was applied to a $2.4 \times 7.0 \mathrm{~cm}$ SP-Sepharose column (GE healthcare Japan cooperation; Asahigaoka, 191-0065 Hino Tokyo Japan) and equilibrated with buffer A. POX was eluted with a linear gradient of $50-500 \mathrm{mM} \mathrm{LiCl}$ in the same buffer. Active fractions were collected and further purified by gel filtration chromatography on a $1.5 \times 55 \mathrm{~cm}$ Sephacryl S-200 column (GE healthcare Japan cooperation) with equilibrated buffer $\mathrm{A}$, which contained 150 $\mathrm{mM} \mathrm{LiCl}$, and eluted with the same buffer. All of the above steps were carried out as soon as possible at $4^{\circ} \mathrm{C}$. In each purification step, POX activity was measured using guaiacol as the substrate. After gel filtration, POX activity became unstable, and did not improve, compared with cation exchange chromatography, following a subsequent purification fold. Therefore, we tried to stabilize POX by adding both $\mathrm{FeCl}_{3}$ and $\mathrm{AlCl}_{3}$. However, addition of these ions caused a decrease in performance after gel filtration (data not shown). We then decided to add $\mathrm{FeCl}_{3}$ or measure enzymatic properties as soon as possible after active fractions were obtained by gel filtration. Using guaiacol as substrate, one unit of POX activity was defined as the amount of enzyme which increased absorbance by $1.0 \mathrm{~min}^{-1}$ at $490 \mathrm{~nm}$. Total protein content was measured using bovine serum albumin (BSA) as the standard protein.

\subsection{Assay of POX Activity}

POX was assayed according to the method of previous report [11]. POX activities were determined at $25^{\circ} \mathrm{C}$ by measuring the initial rate of the increase in absorbance at $490 \mathrm{~nm}$ (guaiacol) and $415 \mathrm{~nm}$ (ABTS), and the decrease in absorbance at $370 \mathrm{~nm}$ (quercetin). The assay mixture contained $50 \mathrm{mM}$ buffer at optimal $\mathrm{pH}, 9.3 \mathrm{mM} \mathrm{H}_{2} \mathrm{O}_{2}, 85$ $\mathrm{mM}$ guaiacol $87 \mathrm{mM}$ ABTS and $0.3 \mathrm{mM}$ quercetin as the substrate.

\subsection{Estimation of Molecular Weight of POX}

Gel filtration chromatography was used to estimate the molecular weight of POX according to the method in previous report [11]. A POX solution was loaded on a 1.5 $\times 55 \mathrm{~cm}$ Sephacryl S-200 column with equilibrated buffer A, which contained $150 \mathrm{mM} \mathrm{LiCl}$. The molecular weight was determined using a calibration curve derived from the following standard proteins: $\beta$-amylase $(200$ $\mathrm{kDa})$, BSA (66 kDa), carbonic anhydrase (29 kDa), and cytochrome C (12.4 kDa).

\subsection{Determination of Optimal $\mathrm{pH}$ and $K_{m}$}

Using guaiacol, ABTS and quercetin as substrates, POX activity was determined under the following $\mathrm{pH}$ levels at $25^{\circ} \mathrm{C}: 2.0$ (50 mM glycine- $\mathrm{HCl}$ buffer); 3.0 - 4.0 (50 mM citrate-LiOH buffer); $5.0-6.0(50 \mathrm{mM}$ acetate-LiOH buffer); 7.0 (50 mM phosphate-LiOH buffer); 8.0 (50 mM Tris-HCl buffer); and $9.0-10.0(50 \mathrm{mM}$ borate-LiOH buffer). $K_{\mathrm{m}}$ was determined by LineweaverBurk plots at different concentrations of each substrate. The substrate mixture contained $1 \mathrm{mM} \mathrm{FeCl}_{3}$.

\subsection{Effect of Various Metal Ions on Purified POX Activity}

After the gel filtration step, purified POX was incubated for $0 \mathrm{~h}, 96 \mathrm{~h}$ and $186 \mathrm{~h}$ at $4^{\circ} \mathrm{C}$ with $1 \mathrm{mM}$ of various metal chlorides $\left(\mathrm{FeCl}_{3}, \mathrm{AlCl}_{3}, \mathrm{CaCl}_{2}, \mathrm{MnCl}_{2}, \mathrm{MgCl}_{2}\right.$, $\mathrm{KCl}$ and $\mathrm{NaCl}$ ), and POX activity was measured using guaiacol as a substrate. Assay was performed according to the method of previous report [11].

\section{RESULTS AND DISCUSSION}

\subsection{Purification of Peroxidase from Tartary Buckwheat Shoots}

POX in Tartary buckwheat shoot was purified by ammonium sulfate precipitation, cation-exchange chromatography and gel filtration (Table 1). We found one large peak corresponding to POX activity on cation-exchange chromatography (Figure 1). In comparison, buckwheat seeds contain at least two peaks corresponding to POX 
Table 1. Purification of the POX in Tartary buckwheat shoots.

\begin{tabular}{|c|c|c|c|c|c|}
\hline Purification step & Total protein $(\mathrm{mg})$ & Total activity units & $\begin{array}{c}\text { Specific activity } \\
\text { (units/mg protein) }\end{array}$ & Yield (\%) & Fold \\
\hline Crude exrtract & 109 & 6390 & 58.7 & 100 & 1.00 \\
\hline Ammonium sulfate precipitation & 44.3 & 5910 & 133 & 92.5 & 2.30 \\
\hline Cation exchange & 0.0374 & 1130 & 2850 & 17.7 & 48.6 \\
\hline Gel filtration & 0.0205 & 579 & 2820 & 9.07 & 48.0 \\
\hline
\end{tabular}

${ }^{\mathrm{a}}$ Changes in absorbance at $490 \mathrm{~nm} / \mathrm{min} \times 10^{3}$ enzyme = 1 unit.; POX activity was measured using guaiacol as a substrate.

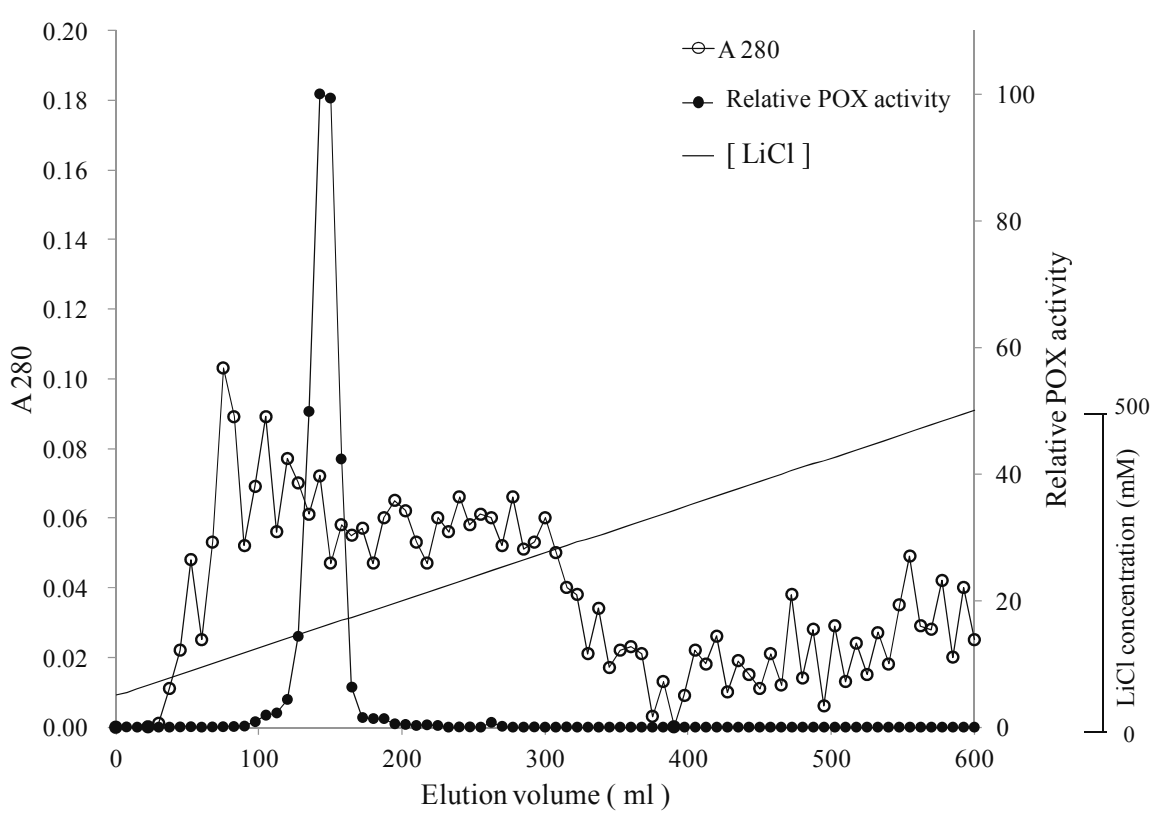

Figure 1. Elution profile of POX activity on the SP-sepharose column

activity $[3,10]$. Therefore, the composition of cationic POX isozymes in Tartary buckwheat shoots must be different from that found in common and Tartary buckwheat seeds. Slight POX activity was also found on anion-exchange chromatography (data not shown), even though anionic POX was too weak to purify. It reported that POX isozymes induced by UV-B radiation in buckwheat seeds differed from those induced in leaves [9]. These results suggest that POX may serve different roles in seeds compared with shoots. Based on gel filtration chromatography, the molecular weight of POX from buckwheat shoots was estimated to be $37.5 \mathrm{kDa}$. This value was smaller than that of POX from both common (46.1 kDa) [10] and Tartary buckwheat seeds $(46.8 \mathrm{kDa})$ [11], but similar to that of both Allium sativa L. (37.8 kDa) [12] and Withania somnifera (34 kDa) [13].

\subsection{Optimal $\mathrm{pH}$ of Purified POX}

The optimal $\mathrm{pH}$ of purified POX was investigated using guaiacol, ABTS and quercetin as substrates, and found to be similar to each substrate used in this study (Table 2). The optimal $\mathrm{pH}$ for guaiacol was 5.5. This value was similar to that of peroxidase from both
Spinacia oleracea leaves (pH 5.2) [14] and Brassica napus L. (pH 5.5) [15]. POX activity decreased with either an increase or a decrease of $\mathrm{pH}$. The optimal $\mathrm{pH}$ for guaiacol in common buckwheat seed was 9.0, which was different from that in POX from Tartary buckwheat shoots [10]. On the other hand, the optimal $\mathrm{pH}$ for guaiacol in Tartary buckwheat seed was 6.0, which was similar to that of POX in Tartary buckwheat shoots for guaiacol [11]. The optimal pH of POX in Tartary buckwheat shoots for ABTS was 5.0. This value was similar to those of peroxidase from Cucumis melo L. (pH 5.5) [16] and Capsicum annuum L. (pH 4.5) [17]. The optimal $\mathrm{pH}$ for quercetin was 5.5 , which was higher than that of peroxidase from both Vitis vinifera and Allium sativum L. $[12,18]$. When quercetin was used as a substrate, POX could retain activity in a wider $\mathrm{pH}$ range compared to guaiacol and ABTS. Buckwheat shoots, and especially leaves and cotyledon, contain a large amount of rutin [3,19] and exhibit rutinosidase activity [19]. When these structures are damaged by UV and cold stress, quercetin is generated from rutin via rutinosidase activity [3]. Therefore, a wider $\mathrm{pH}$ range of POX activity against quercetin may relate to quercetin metabolism in vivo. 
Table 2. Optimum $\mathrm{pH}$ of purified POX.

\begin{tabular}{|c|c|c|c|}
\hline \multirow[b]{2}{*}{$\mathrm{pH}$} & \multicolumn{3}{|c|}{ Relative activity (\%) ${ }^{\mathrm{a}}$} \\
\hline & Guaiacol & ABTS & Quercetin \\
\hline 2.0 & n.d. $^{b}$ & $56.8 \pm 8.0$ & $14.0 \pm 0.7$ \\
\hline 3.0 & n.d. & $5.6 \pm 2.8$ & $39.4 \pm 0.6$ \\
\hline 4.0 & $34.0 \pm 1.0$ & $48.3 \pm 1.6$ & $88.2 \pm 2.7$ \\
\hline 5.0 & $78.2 \pm 1.0$ & $\underline{100} \pm 4.4$ & $94.1 \pm 4.0$ \\
\hline 5.5 & $\underline{100} \pm 1.2$ & $55.2 \pm 1.4$ & $\underline{100} \pm 0.2$ \\
\hline 6.0 & $50.4 \pm 1.5$ & $26.7 \pm 0.9$ & $95.0 \pm 2.4$ \\
\hline 7.0 & n.d. & $12.2 \pm 1.8$ & $83.5 \pm 1.6$ \\
\hline 8.0 & $1.3 \pm 0.3$ & n.d. & $35.5 \pm 0.1$ \\
\hline 9.0 & $1.7 \pm 0.5$ & n.d. & $24.9 \pm 0.3$ \\
\hline 10.0 & $0.8 \pm 0.2$ & n.d. & $12.9 \pm 1.4$ \\
\hline
\end{tabular}

${ }^{\mathrm{a}}$ Guaiacol and quercetin: $\mathrm{pH} 5.5=100 \%$; ABTS: pH $5=100 \%$; ${ }^{\mathrm{b}}$ Not detected.; Date are means \pm SD $(n=3)$.

This reinforces the idea that the anti-fungal agent 3,4dihydroxybenzoic acid is formed by peroxidase-dependent oxidation of quercetin on browning onion scales [20].

\subsection{Effect of Metal Ions on Purified POX Activity}

After gel-filtration chromatography, the effects of various metal ions on purified POX activity were investigated at $0 \mathrm{~h}, 96 \mathrm{~h}$ and $186 \mathrm{~h}$ in storage (Table 3). At $0 \mathrm{~h}$, POX activity ranged between $93.8 \%\left(\mathrm{CaCl}_{2}\right)$ to $127 \%$ $\left(\mathrm{FeCl}_{3}\right)$ compared to the activity without metal ions (= defined as $100 \%$ ). After storage at $96 \mathrm{~h}$ and $186 \mathrm{~h}$, POX did not retain activity in either the absence or presence of divalent and monovalent metal ions. On the other hand, when $\mathrm{FeCl}_{3}$ or $\mathrm{AlCl}_{3}$, where added POX activity was retained even after storage at $186 \mathrm{~h}$ at $83.6 \%\left(\mathrm{FeCl}_{3}\right)$ and $56.1 \%\left(\mathrm{AlCl}_{3}\right)$. These results suggest that POX in Tartary buckwheat shoots can be stabilized by trivalent metal ions. In addition, it suggests that $\mathrm{FeCl}_{3}$ stabilizes POX more effectively than $\mathrm{AlCl}_{3}$. Numerous reports have shown that POX is activated by divalent ions such as $\mathrm{Ca}^{2+}$ ions $[21,22]$. On the other hand, only a few studies have reported that POX is activated by both $\mathrm{Fe}^{3+}[23]$ and $\mathrm{Al}^{3+}$ [24]. In addition, in these reports, POX activities were activated only about 2.1 to 3.3 folds. However, no studies have found that the stability of POX is enhanced in the presence of trivalent metal ions. Therefore, our finding reveals novel characteristics concerning POX and suggests the importance of studying its physiological roles in plants.

\subsection{Kinetics of Purified POX}

We measured the $K_{m}$ of POX both in the presence and absence of $\mathrm{FeCl}_{3}$ and $\mathrm{AlCl}_{3}$ using guaiacol, ABTS and quercetin as substrates. The results are summarized in Table 4. In the absence of the trivalent ions, $K_{\mathrm{m}}$ values
Table 3. Effect of metal ions on POX activity.

\begin{tabular}{cccc}
\hline \multicolumn{4}{c}{ Relative activity $(\%)^{\mathrm{a}}$} \\
\hline Compounds & $0 \mathrm{~h}$ & $96 \mathrm{~h}$ & $186 \mathrm{~h}$ \\
\hline Non & $\underline{100}^{\mathrm{b}} \pm 2.2$ & n.d. & n.d. \\
$\mathrm{FeCl}_{3}$ & $127 \pm 2.4$ & $118.5 \pm 0.5$ & $83.6 \pm 2.7$ \\
$\mathrm{AlCl}_{3}$ & $102 \pm 4.0$ & $108.8 \pm 0.3$ & $56.1 \pm 2.7$ \\
$\mathrm{CaCl}_{2}$ & $93.8 \pm 10.3$ & n.d. & n.d. \\
$\mathrm{MnCl}_{2}$ & $99.6 \pm 8.3$ & n.d. & n.d. \\
$\mathrm{MgCl}_{2}$ & $100 \pm 17.8$ & n.d. & n.d. \\
$\mathrm{KCl}$ & $108 \pm 8.6$ & n.d. & n.d. \\
$\mathrm{NaCl}$ & $106 \pm 2.4$ & n.d. & n.d. \\
\hline
\end{tabular}

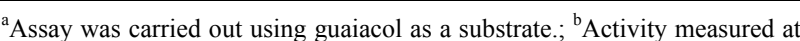
$0 \mathrm{~h}$ in metal ion free condition is $100 \%$; ; Date are means $\pm \mathrm{SD}(\mathrm{n}=3)$.

Table 4. $K_{m}$ of purified POX.

\begin{tabular}{cccc}
\hline Substrate & \multicolumn{3}{c}{$K_{m}(\mathrm{mM})$} \\
\cline { 2 - 4 } & $-^{\mathrm{a}}$ & $1 \mathrm{mM} \mathrm{FeCl}_{3}$ & $1 \mathrm{mM} \mathrm{AlCl}_{3}$ \\
\hline Guaiacol & 22.3 & 16.4 & 7.50 \\
ABTS & 6.30 & 0.86 & 11.5 \\
Quercetin & 0.92 & 0.018 & 19.1 \\
\hline
\end{tabular}

${ }^{\mathrm{a}}$ Absence of trivalent metal ions.

were $22.3 \mathrm{mM}, 6.3 \mathrm{mM}$ and $0.92 \mathrm{mM}$ for guaiacol, ABTS and quercetin, respectively. Compared to POX in other plants, the $K_{m}$ for guaiacol was higher than that from Jastropha curcas leaves $(0.17 \mathrm{mM})[25]$ and Brassica napus roots $(3.7 \mathrm{mM})$ [15]. The $K_{m}$ for ABTS was also higher than that from Eupatrium odoratutum $(0.12$ $\mathrm{mM})$ [26] and Brassica napus roots $(0.7 \mathrm{mM})$ [15]. In addition, the $K_{m}$ for quercetine was much higher than that from both Allium sativum L. (0.033 mM) [12] and Vicia $f a b a$ leaves $(0.023 \mathrm{mM})$ [27]. Furthermore, the presence of $\mathrm{FeCl}_{3}$ enhanced the affinity of POX, resulting in a decreased $K_{m}$ of $16.4 \mathrm{mM}, 0.86 \mathrm{mM}$ and $0.018 \mathrm{mM}$ for guaiacol, ABTS and quercetin, respectively. The presence of $\mathrm{FeCl}_{3}$ led to a dramatic decrease of $K_{m}$, about 51.1 fold, for quercetin compared to its absence, which, when compared to the $K_{m}$ for quercetin in other plants, is one of the lowest values so far reported in: both common buckwheat seed $(0.028 \mathrm{mM})$ [10] and Vicia faba leaves $(0.023 \mathrm{mM})$ [27]. On the other hand, the presence of $\mathrm{AlCl}_{3}$ increased the $K_{m}$ for quercetin about 20 fold compared to $K_{m}$ in its absence. These results suggest that POX has different mechanisms for controlling its activity in relation to both $\mathrm{FeCl}_{3}$ and $\mathrm{AlCl}_{3}$. Based on these results, we suggest that POX in Tartary buckwheat shoots have unique characteristics, and novel aspects related to the physiological roles of POX that warrant for further investigation. 


\section{ACKNOWLEDGEMENT}

We thank to Mr. S. Nakamura and Mr. T. Fukaya for their assistance in the field. We also thank to Ms. K. Fujii, Ms. M. Hayashida and Ms. T. Ando for their technical assistance.

\section{REFERENCES}

[1] Kitabayashi, H., Ujihara, A., Hirose T. and Minami, M. (1995) Varietal differences and heritability for rutin content in common buckwheat, Fagopyrum esculentum Moench. Breeding Science, 45, 75-79.

[2] Kitabayashi, H., Ujihara, A., Hirose, T. and Minami, M. (1995b) On the genotypic differences for rutin content in Tartary buckwheat, Fagopyrum tataricum Gaerth. Breeding Science, 45, 189-194

[3] Suzuki, T., Honda, Y. and Mukasa, Y. (2005) Effect of UV-B radiation, cold and desiccation stress on rutin concentration and rutin glucosidase activity in tartary buckwheat (Fagopyrum tataricum) leaves. Plant Science, 168, 1303-1307. doi:10.1016/j.plantsci.2005.01.007

[4] Dadakova, E. and Kalinova, J. (2010) Determination of quercetin glycosides and free quercetin in buckwheat by caplillary micellar electrokinetic chromatography. Journal of Separation Science, 33, 1633-1638. doi:10.1002/jssc. 200900809

[5] Fabjan N, Rode J, Kosir IJ, Wang Z, Zhang Z and Kreft I. (2003) Tartary buckwheat (Fagopyrum tataricum Gaertn.) as a source of dietary rutin and quercitrin. Journal of $\mathrm{Ag}$ ricultural and Food Chemistry, 51, 6452-6455. doi:10.1021/if034543e

[6] Suzuki, T., Watanabe, M., Iki, M., Aoyagi, Y., Kim, S.J., Mukasa, Y., Yokota, S., Takigawa, S., Hashimoto, N., Noda, T., Yamauchi, H. and Matsuura, C. (2009) Timecourse study and effects of drying method on concentrations of $\gamma$-aminobutyric acid, flavonoids, anthocyanin, and 2'-hydroxynicotianamine in leaves of buckwheats. Journal of Agricultural and Food Chemistry, 57, 259-264. doi:10.1021/jf802731d

[7] Harborne, J.B. and Williams, A.C. (2000) Advances in flavonoid research since 1992. Phytochemistry, 55, 481504. doi:10.1016/S0031-9422(00)00235-1

[8] Logrimini, L.M. and Rothstein, S. (1987) Tissue specificity of tobacco peroxidase isozymes and their induction by wounding and tobacco mosaic virus infection. Plant physiology. 84, 438-442. doi:10.1104/pp.84.2.438

[9] Jovanovic, Z.S., Milosevic, J.D. and Radovic, S.R. (2006) Antioxidative enzymes in the response of buckwheat (Fagopyrum esculentum Moench) to ultraviolet B radiation. Journal of Agricultural and Food Chemistry, 54, 9472-9478. doi:10.1021/jf061324v

[10] Suzuki, T., Honda, Y., Mukasa, Y. and Kim, S.J. (2006) Characterization of peroxidase in buckwheat seed. Phytochemistry, 67, 219-224. doi:10.1016/j.phytochem.2005.11.014

[11] Suzuki, T., Shin, D.H., Woo, S.H., Mukasa, Y., Morishita, T., Noda, T., Takigawa, S., Hashimoto, N., Yamauchi, H. and Matsuura-Endo, C. (2012) Caracterization of peroxi- dase in Tartary buckwheat seed. Food Science and Technology Research, 18, 571-575. doi:10.3136/fstr.18.571

[12] Marzouki, M.S., Almagro, L., Sabater-Jara, B.A., Barcelo, R. and Pedreno, A. (2010). Kinetic characterization of a basic peroxidase from Garlic (Allium sativum L.) cloves. Journal of Food Science, 75, 740-746. doi:10.1111/j.1750-3841.2010.01848.x

[13] Johri, S., Jamwal, U., Rasool, S., Kumar, A., Verma, V. and Qazi, G.N. (2005) Purification and characterization of peroxidases from Withania somnifera (AGB 002) and their ability to oxidize IAA. Plant science, 169, 10141021. doi:10.1016/j.plantsci.2005.05.015

[14] Koksal, E. (2011) Peroxidase from leaves of spinach (Spinacia oleracea): Partial purification and some biochemical properties. International Journal of Pharmacology, 7, 135-139.

[15] Duarte-Vazquez, M.A., Garacia-Almendarez, B.E., Regalado, C. and Whitaker, J.R. (2001) Purification and properties of a neutral peroxidase isozyme from turnip (Brassica napus L. var. purple Top White Globe) root. Journal of Agricultural and Food Chemistry, 49, 44504456. doi:10.1021/jf010043e

[16] Rodriguez-Lopez, N., Espin, J.C., Amor, F.D., Tudela, J., Martines, V., Cerda, A. and Garcia-Canovas, F. (2000) Purification and kinetic characterization of an anionic peroxidase from melon (Cucumis melo L.) cultivated under different salinity conditions. Journal of Agricultural and Food Chemistry, 48, 1537-1541. doi:10.1021/jf9905774

[17] Serrano-Martinez, A., Fortea, I.M., Amor, M.F. and Nunez-Delicado, E. (2008) Kinetic characterization and thermal inactivation study of partially purified red pepper (Capsicum annuum L.) peroxidase. Food Chemistry, 107, 193-199. doi:10.1016/j.foodchem.2007.08.028

[18] Morales, M. and Barcelo, R.A. (1997) A basic peroxidase isozyme from vacuoles and cell walls of Vitis vinifera. Phytochemistry, 45, 229-232. doi:10.1016/S0031-9422(96)00825-4

[19] Suzuki, T., Kim, S.J., Takigawa, S., Mukasa, Y., Hashimoto, N., Saito, K., Noda, T., Matsuura-Endo, C., Zaidul, I.S.M. and Yamauchi, H. (2007) Changes in rutin concentration and flavonol-3-glucosidase activity during seedling growth in Tartary buckwheat (Fagopyrum tataricum Gaertn). Canadian Journal of Plant Science, 87, 83-87. doi:10.4141/P05-151

[20] Takahama, U. and Hirota, S. (2000). Deglucosidase of quercetin glucosides to the aglycone and formation of antifungal agents by peroxidase dependent oxidation of quercetin on browing of onion scales. Plant and Cell Physiolpgy, 41, 1021-1029. doi:10.1093/pcp/pcd025

[21] Mura, A., Lougu, S., Padiglia, A., Rinaldi, C.A., Floris, G. and Medda, R. (2005) Reversible thermal inactivation and conformational states in denaturant guanidium of a calcium-dependent peroxidase from Euphorbia characias. International Journal of Biological Macromolecules, 37, 205-211. doi:10.1016/j.ijbiomac.2005.10.010

[22] Mohamed, A.S., Abulnaja, O.K., Ads, S.A., Khan, A.J. and Kumosani, A.T. (2011) Characterisation of an anionic peroxidase from horseradish cv. Balady. Food Chemistry, 
128, 725-730. doi:10.1016/j.foodchem.2011.03.096

[23] Manu, B.T. and Rao, U.S.J.P. (2009) Calcium modulated activity enhancement and thermal stability study of a cationic peroxidase purified from wheat bran. Food Chemistry, 114, 66-71. doi:10.1016/j.foodchem.2008.09.028

[24] Onsa, H.G., Saari, B.N., Selamat, J. and Bakar, J. (2004) Purification and characterization of membrane-bound peroxidases from Metroxylon sagu. Food Chemistry, 85, 365-376. doi:10.1016/j.foodchem.2003.07.013

[25] Cai, F., Yang, C., Duan, P., Gao, S., Xu, Y. and Chen, F. (2012) Purification and characterization of a novel ther- mal stable peroxidase from Jastropha curcas leaves. Journal of Molecular Catalysis B: Enzymatic, 77, 59-66. doi:10.1016/j.molcatb.2011.12.002

[26] Rani, D.N. and Abraham, T.E. (2006) Kinetic study of a purified anionic peroxidase isolated from Eupatorium odoratum and its novel application as time temperature indicator for materials. Journal of Food Engineering, 77, 594-600.

[27] Takahara, U. and Egashira, T. (1991) Peroxidases in vacuoles of Vicia faba leaves. Phytochemistry, 30, 73-77. doi:10.1016/0031-9422(91)84101-W

\section{ABBREVIATIONS}

ABTS: 2,2'-azino-bis(3-ethylbenzthiazoline-6-sulphonic acid);

DW: dry weight. 